\title{
Sentimentos Maternos frente ao Desenvolvimento da Criança aos 12 Meses: Convivendo com as Novas Aquisições Infantis ${ }^{1}$
}

\author{
Rita de Cássia Sobreira Lopes ${ }^{2}$ \\ Débora S. de Oliveira \\ Aline Groff Vivian \\ Lúcia Martins Costa Bohmgahren \\ Cesar Augusto Piccinini \\ Universidade Federal do Rio Grande do Sul \\ Jonathan Tudge \\ University of North Carolina
}

\begin{abstract}
RESUMO - Aos 12 meses a criança apresenta novas aquisições de linguagem e locomoção que a permitem realizar movimentos de afastamento e reaproximação do cuidador. Assim, a mãe ocupa papel fundamental, pois deve proporcionar oportunidades para descobertas e favorecer explorações. Este estudo investigou o desenvolvimento da criança aos 12 meses e os sentimentos maternos em relação a esse momento. Participaram 28 mulheres, de nível socioeconômico variado, com idades entre 20 e 37 anos, cujos filhos tinham 12 meses. Foi realizada uma entrevista semi-estruturada sobre a experiência da maternidade e o desenvolvimento da criança. A análise de conteúdo revelou a riqueza das novas aquisições e seu impacto nos sentimentos maternos. As mães relataram sentimentos ambivalentes de gratificação e realização, mas também de maior demanda e dedicação. Dada a importância desse período, torna-se fundamental que a mãe seja capaz de adaptar-se às novas aquisições infantis e que esteja disponível para partilhar de suas experiências.
\end{abstract}

Palavras-chave: sentimentos maternos; desenvolvimento infantil; crianças aos 12 meses.

\section{Maternal Feelings concerning Child Development at 12 Months Old: Living with the Child's New Acquisitions}

\begin{abstract}
When the child is 12 months old he/she acquires new language and locomotion abilities, which allows him/her to both move away and get close to the caretaker. Thus, the mother holds a fundamental role, since she must give the child opportunities for discoveries and explorations. This study investigated child's development at 12 months old as well as maternal feelings in relation to this moment. Twenty-eight women aged 20 to 37, of different social economic level, whose child was 12 months old, took part in the study. A semi-structured interview about motherhood experience and child's development was carried out. The content analysis revealed the richness of the new acquisitions and their impact on maternal feelings. Mothers reported ambivalent feelings of gratification and fulfillment, but also of greater demand and dedication. Given the importance of this period, it is crucial that the mother should be able to adapt to child's new acquisitions and be available to share their experiences.
\end{abstract}

Key words: maternal feelings; child development; one-year-old children.

O final do primeiro ano de vida caracteriza-se como um momento importante do desenvolvimento infantil, uma vez que a criança apresenta novas aquisições em termos de linguagem, locomoção e exploração do ambiente. Essas mudanças acabam tendo um impacto nos sentimentos maternos com relação a elas. Assim, as novas capacidades da criança constituem um desafio para a mãe, que precisa adaptar-se às novas exigências e aprender a entender como lidar com as aquisições que surgem nesse período do desenvolvimento.

Em pesquisa realizada em bancos de dados (BVS-Psi, EBSCOhost, Lilacs, Medline, PsychInfo e Scielo) foram

1 Agradecemos ao CNPq e a Spencer Foundation pelo auxílio financeiro recebido.

2 Endereço: Instituto de Psicologia, Universidade Federal do Rio Grande do Sul. Rua Ramiro Barcelos 2600, Porto Alegre, RS, Brasil 90035-003. E-mail: sobreiralopes@porto.com.br encontrados estudos empíricos internacionais que abordam a sensibilidade materna na interação com a criança de 12 meses (Kivijärvi \& cols., 2001; Lohaus, Keller, Ball, Voelker \& Elben, 2004), efeitos da interferência materna no comportamento exploratório de crianças aos 12 meses (Gray, Tracy \& Lindberg, 1979), parentalidade e desenvolvimento da criança de um ano de idade (Van Bakel \& Riksen-Walraven, 2002), correlações cognitivas da atenção infantil e estimulação materna durante o primeiro ano de vida (Ruddy \& Borenstein, 1982), comportamento social espontâneo de crianças de um ano de idade com suas mães (Wenar, 1972). Outros estudos enfatizaram a competência e auto-eficácia materna (Teti \& Gelfand, 1991; Veddovi, Gibson, Kenny, Bowen \& Starte, 2004) e atitudes maternas na criação dos filhos aos 12 meses (Benasich \& Brooks-Gunn, 1996), porém não abordaram a temática de sentimentos frente às aquisições durante o primeiro ano de vida. Mais especificamente sobre o desenvolvimento 
da criança aos 12 meses, foram encontrados estudos que abordaram as estratégias de locomoção (McKenzie, Lawrence \& Connell, 1995), além de atenção e manipulação de brinquedos (Fenson, Sapper \& Minner, 1974) e desenvolvimento sensoriomotor (Johnson \& Brody, 1977).

Em contexto brasileiro foram encontrados estudos que examinaram a depressão materna e a interação mãe-bebê no final do primeiro ano de vida (Schwengber \& Piccinini, 2004) e, mais especificamente, sobre o desenvolvimento motor aos 12 meses (Mancini \& cols. 2002). Também foram encontradas revisões teóricas que abordaram a interação mãe-criança (Zamberlan, 2002) e a responsividade materna (Ribas \& Seidl de Moura, 2004). Embora autores tenham se dedicado aos estudos do primeiro ano de vida do bebê, não foram encontradas pesquisas quanto aos sentimentos maternos com relação às novas aquisições desse momento de vida da criança. Dessa forma, pretende-se, com o presente artigo, contribuir para um melhor entendimento sobre o desenvolvimento da criança aos 12 meses, sobretudo quanto aos sentimentos maternos frente às novas aquisições infantis nesse momento.

Ao longo do primeiro ano de vida, a criança apresenta mudanças expressivas em seu desenvolvimento que vão desde o crescimento físico até o emocional, com destaque para o incremento das habilidades de linguagem, locomoção e de exploração - uma vez que passa a apresentar uma maior capacidade para realizar movimentos de afastamento e de reaproximação (Brazelton, 2002; Newcombe, 1999). No decorrer desse período, a criança costuma buscar cada vez mais a atenção de sua mãe, bem como se interessar por objetos escondidos e pela brincadeira de esconde-esconde (Stern, 1991). Ao final do primeiro ano, o bebê começa a manifestar, de maneira muito clara, comportamentos característicos de separação em relação ao cuidador. Esse processo torna-se possível pelas novas capacidades do bebê de afastar-se da mãe e de retornar a ela.

A partir de estudos sobre a dependência emocional do bebê e o papel da mãe como facilitadora desses movimentos de separação, Mahler e colegas (Mahler, 1979/1982; Mahler, Pine \& Bergman, 1975/2002) destacaram que o processo de separação e de individuação da criança ocorre paralelamente à maturação e à integração das funções autônomas do ego, como motilidade e linguagem. Contudo, essas tendências individuais inatas para a integração e o crescimento, que variam de um indivíduo para outro, não são as únicas a garantir o desenvolvimento emocional, cognitivo e social, dependendo também dos cuidados maternos e da qualidade do próprio ambiente (Winnicott, 1979/1983; Mahler \& cols., 1975/2002).

Aos 12 meses de idade, o bebê aprende a andar, imita comportamentos dos adultos, gosta de tomar decisões e iniciativas e, geralmente, quer ter o controle de suas separações em relação aos pais, não tolerando que estes se afastem dele (Brazelton, 2002). As novas aquisições de habilidades motoras acabam repercutindo nas rotinas do cotidiano do bebê, como em atividades do sono e alimentação, entre outras. Além disso, essas capacidades possibilitam à criança adquirir novas perspectivas sobre os objetos e situações, além de utilizá-las como parte de seu comportamento exploratório. Cabe ressaltar que essas aquisições iniciadas no primeiro ano continuam ocorrendo ao longo do desenvolvimento infantil.
Como decorrência dessas aquisições por parte da criança, desencadeia-se um processo de afastamentos e reaproximações iniciados pelo bebê, ao qual a mãe precisa se adaptar. Mahler e colegas (Mahler, 1979/1982; Mahler \& cols., 1975/2002) observaram mães e bebês durante os três primeiros anos de vida e verificaram que a individuação da criança só era alcançada por um processo evolutivo chamado processo de separaçãoindividuação. A garantia do processo normal está associada ao ambiente, representado pela mãe, cuja disponibilidade física e emocional deve se adaptar à evolução da criança. Assim, o processo de separação psicológica ocorre quando a criança passa a separar-se emocionalmente de seus cuidadores, estabelecendo novas relações com o mundo desde que nasceu. O processo de separação-individuação, portanto, vincula-se tanto a uma disposição da criança para um funcionamento independente quanto ao ambiente e ao modo como ocorrem as relações pais e criança.

Tendo presente que a criança aos 12 meses apresenta diversas habilidades, bem como uma incipiente separação emocional da mãe, é plausível supor que esse momento seja de extrema importância para o desenvolvimento infantil e para os próprios pais. Contudo, para que a criança possa explorar ativamente seu ambiente e apresentar um senso de iniciativa e de curiosidade, é preciso que cuidadores e, sobretudo a mãe, se comportem como organizadores do ambiente da criança (Elkind, 2004; Mahler \& cols., 1975/2002; Stern, 1991; Winnicott, 1979/1983). Estes devem adaptar-se em alto grau às necessidades do filho e estarem disponíveis para partilhar de suas explorações e auxiliarem em suas tentativas de imitação e de identificação, fornecendo assim um cuidado satisfatório e um ambiente confiável. Para Winnicott (2000), as tarefas ligadas aos primeiros estágios do desenvolvimento emocional da criança só podem ser levadas a cabo em um ambiente suficientemente bom. Esse ambiente, principalmente nesses períodos iniciais, deve adaptar-se ativamente às necessidades do bebê, colocando-se de modo empático ao atendimento de suas demandas. Logo, um ambiente suficientemente bom, proporcionado pelos cuidados fornecidos sobretudo pela mãe, capacita o bebê a ter novas experiências, a constituir um ego pessoal individualizado, a dominar seus instintos e a defrontar-se com as dificuldades inerentes à vida (Winnicott, 1979/1983).

No que se refere ao desenvolvimento infantil, especificamente aos 12 meses, a criança é capaz de realizar afastamentos físicos propiciados por uma maior habilidade motora, tendo ainda a mãe como base segura (Ainsworth, Blehar, Waters \& Wall, 1978; Bowlby, 1989; Mahler, 1979/1982). Além disso, Mahler e cols. (1975/2002) apontaram que a mãe deve desempenhar a necessária função de reabastecimento emocional no retorno do bebê, já que seu empenho explorador dura apenas períodos curtos de tempo. Nesse sentido, a função materna é permitir liberdade para o bebê distanciar-se e oportunidade para explorar o ambiente, bem como estar disponível física e emocionalmente no momento de seu retorno. Brazelton (2002) indicou que a mãe precisa decodificar os sinais que evidenciam a autonomia do bebê sem sentir-se rejeitada. Uma mãe incapaz de tolerar a independência da criança aos 12 meses tende a ignorar e a passar por cima desse importante salto no desenvolvimento de seu bebê. Ele também referiu que embora a mãe pudesse se sentir rejeitada é possível que ela 
se sentisse ainda mais necessária para proporcionar ao filho essas novas experiências e confirmar sua competência. Assim, a maneira como a mãe atende às necessidades do filho pode ter importantes repercussões no desenvolvimento emocional da criança.

Os sentimentos maternos que surgem nessa fase do desenvolvimento do bebê são variados e intensos, conforme aponta a literatura (Brazelton, 2002; Zamberlan, 2002; Prado, 1996; Mahler, 1979/1982; Mahler \& cols., 1975/2002; Winnicott, 1979/1983, 1989/1999, 1965/2001). Brazelton (2002) referiu que o relacionamento familiar, mais especificamente com os cuidadores - pai ou mãe - contribui para o desenvolvimento emocional e comportamental da criança, bem como para a sua jornada rumo à autonomia. $\mathrm{O}$ desenvolvimento motor, emocional, cognitivo e social não é linear e podem ocorrer avanços e regressões de habilidades já adquiridas pela criança. Dessa forma, os sentimentos maternos durante esse período do desenvolvimento da criança também podem variar. Brazelton (2002) mencionou, ainda, que os pais quase sempre enfrentam com ansiedade a eventual regressão em algum comportamento de seu filho na época em que este está buscando sua autonomia. Entretanto, se os pais puderem compreender a necessidade que a criança tem de estabelecer o seu próprio padrão de autonomia, poderão aprender a entender a separação e os sentimentos dela decorrentes sem que se perca a intensidade da relação. Nesse sentido, ao compreender que a dor da separação é, primeiramente, uma dificuldade dos pais, poderão aprender a lidar de melhor maneira com ela.

Considerando que o final do primeiro ano de vida é importante tanto para o bebê como para a mãe, faz-se necessária a compreensão dos sentimentos maternos associados a essa fase do desenvolvimento infantil. Prado (1996) referiu que a mãe pode sentir-se pressionada pelas exigências do bebê e tudo que o envolve, podendo chegar ao extremo de sentir-se incapaz de assumi-lo. Uma das formas de neutralizar esses sentimentos maternos é o apoio de familiares mais próximos, em especial do marido ou companheiro. Por outro lado, algumas mães se sentem intensamente ligadas ao filho, de forma que essas múltiplas funções não as fazem sentir-se exauridas, principalmente se tiverem alguém que lhes dê apoio e as auxilie nos cuidados com o bebê.

Assim sendo, o objetivo deste estudo foi o de investigar os sentimentos maternos frente ao desenvolvimento da criança aos 12 meses de idade, em particular com relação às suas novas aquisições.

\section{Método}

\section{Participantes}

Participaram desse estudo 28 mulheres, com idade entre 20 e 37 anos, e que tinham um único filho(a) com 12 meses de idade. As famílias eram de nível socioeconômico variado, residentes na região metropolitana de Porto Alegre e o marido ou companheiro, pai da criança, residia junto. Em termos de escolaridade da amostra do presente estudo, as mulheres variaram entre ensino fundamental $(10,7 \%)$ e completo $(7,1 \%)$, ensino médio incompleto $(7,1 \%)$ e completo $(21,4 \%)$, superior incompleto $(21,4 \%)$ e completo $(32,1 \%)$. Em termos de status ocupacional, $25 \%$ das mães não trabalhavam enquanto as demais tinham profissões classificadas como de baixo status ( $10,7 \%$ de uma a quatro), médio (32,1\% de cinco a seis) e alto status (32,1\% de sete a nove), de acordo com a escala de Hollingshead (Hollingshead, 1975; Tudge \& Frizzo, 2002).

A amostra foi selecionada, com base nos critérios descritos, entre os participantes do Estudo longitudinal de Porto Alegre: da gestação à escola (Piccinini, Tudge, Lopes \& Sperb, 1998). Esse estudo iniciou acompanhando 89 gestantes que não apresentavam intercorrências clínicas, seja com elas mesmas ou com o bebê, o qual era seu primeiro filho. Os maridos ou companheiros também foram convidados a participar do estudo caso residissem juntos em situação matrimonial. Os participantes representavam várias configurações familiares (nucleares, monoparentais ou re-casados), de diferentes idades (adultos e adolescentes) e com escolaridade e níveis sócio-econômicos variado. O estudo envolveu várias fases coletas de dados, desde a gestação até os 7 anos da criança (gestação, 3o, $8^{\circ}, 12^{\circ}, 18^{\circ}$, $24^{\circ}, 30^{\circ}$ meses e $6^{\circ}$ e $7^{\circ}$ ano de vida da criança), e teve por objetivo investigar tanto os aspectos subjetivos e comportamentais das interações iniciais pai-mãe-bebê, assim como o impacto de fatores iniciais do desenvolvimento nas interações familiares, no comportamento social de crianças pré-escolares e na transição para a escola de ensino fundamental. O convite inicial para participar do estudo ocorreu quando a gestante fazia pré-natal em hospitais da rede pública da cidade de Porto Alegre $(51,2 \%)$, nas unidades sanitárias de saúde do mesmo município $(7,3 \%)$, por anúncio em veículos de comunicação $(26,8 \%)$ e por indicação $(14,6 \%)$.

Afora os dados sóciodemográficos coletados na gestação, o presente estudo considerou apenas dados obtidos na quarta fase de coleta de dados, quando a criança estava com 12 meses de idade.

\section{Instrumentos e procedimentos}

Os sentimentos maternos frente ao desenvolvimento da criança foram investigados por meio de entrevista respondida pela mãe quando a criança estava com 12 meses de idade. As famílias, que já vinham sendo acompanhadas desde a gestação do filho, foram novamente contatadas, quando se agendava um novo encontro na Sala de Brinquedos da Universidade Federal do Rio Grande do Sul. Nessa ocasião, a mãe respondia a Entrevista sobre a Experiência da Maternidade e o Desenvolvimento do Bebê aos Doze Meses (1998a), entre outros instrumentos de coleta de dados, que não foram considerados no presente estudo ${ }^{3}$. Essa entrevista estruturada era composta de temas sobre desenvolvimento infantil, experiência da maternidade, percepções maternas sobre os cuidados paternos com relação à criança e à participação de outros cuidadores e da creche. A entrevista foi realizada de

3 Inicialmente a família participava da Observação filmada da interação familiar no primeiro ano do bebê, realizada na Sala de Brinquedos. O pai, quando presente, respondia a Entrevista sobre a experiência da paternidade e o desenvolvimento do bebê aos doze meses. O casal, quando era o caso, respondia a Entrevista com o casal sobre a experiência da parentalidade; a Entrevista sobre as Impressões dos pais sobre o temperamento do bebê. A mãe respondia ainda o Inventário Beck de Depressão. 
forma semidirigida e o entrevistador foi orientado a explorar as respostas maternas.

Além da entrevista com a mãe, foram considerados para o presente estudo dados oriundos da Ficha de Contato Inicial (GIDEP, 1998b), que buscava investigar se a mãe e a família se adequavam aos critérios de inclusão no estudo. Foi utilizada também a Entrevista de Dados Demográficos (GIDEP, 1998c), cujos dados permitiram caracterizar a escolaridade e o nível socioeconômico dos participantes. Ambos os instrumentos foram respondidos pela mãe ainda na gestação.

O projeto longitudinal, do qual o presente estudo faz parte, foi aprovado pela Comissão de Pesquisa e Ética em Saúde do Hospital de Clínicas de Porto Alegre (CPPG/HCPA) por meio da Resolução $\mathrm{n}^{\circ}$ 98293. Essa pesquisa foi considerada ética e metodologicamente adequada, de acordo com as Diretrizes e Normas Regulamentadoras de Pesquisa envolvendo Seres Humanos (Resolução 196/96 do Conselho Nacional de Saúde) e, também, de acordo com as Resoluções Normativas do CPPG/HCPA. Por fim, o Termo de Consentimento Livre e Esclarecido foi assinado pelas participantes que concordaram em fazer parte do presente estudo.

\section{Resultados}

Foi realizada uma análise de conteúdo qualitativa (Laville \& Dionne, 1999; Bardin, 1977) para se investigar os sentimentos maternos das 28 participantes do presente estudo frente ao desenvolvimento da criança aos 12 meses, em particular quanto as suas novas aquisições. As entrevistas contemplaram diversos aspectos do desenvolvimento infantil e da relação mãe-criança, contudo foram consideradas, para fins de análise do presente estudo, somente as questões destacadas a seguir: Como está o desenvolvimento/crescimento do/a (nome)?; $O$ que ele é capaz de fazer que te chama mais a atenção (quais as suas habilidades)?; O bebê já está caminhando? Quando foi o início? Como foi?; Como tu descreverias o jeito do teu bebê, agora, com um ano?"; Como você está se sentindo como mãe nesse momento?; Como te sentes com isso (o bebê estar caminhando)?; Quais foram os momentos em que vocês tiveram que ficar longe?. Caso o conteúdo investigado nessas questões aparecesse em outros momentos da entrevista, era também considerado para fins de análise.

Com base nas respostas das próprias mães, emergiram duas categorias temáticas utilizadas na análise de todas as entrevistas: 1) As novas aquisições da criança; e, 2) Sentimentos maternos frente às novas aquisições da criança. Duas das autoras do presente estudo classificaram separadamente os relatos das mães em cada categoria e, em caso de discordância, utilizou-se um terceiro juiz. Apresenta-se, a seguir, a caracterização de cada uma das categorias, buscando exemplificá-la por relatos maternos.

\section{As novas aquisições da criança aos 12 meses}

Essa primeira categoria temática refere-se ao relato das mães acerca de sua percepção sobre o desenvolvimento e crescimento de seu filho aos 12 meses, em particular quanto as suas novas aquisições. Como subcategorias temáticas destacaram-se: o desenvolvimento e o crescimento aos 12 meses; habilidades da criança que mais chamavam a atenção da mãe; mudanças no comportamento de passividade para maior atividade; comportamento exploratório e locomoção. As mães relataram que, nesse momento, seus filhos pareciam estar mais espertos, demonstravam maior decisão, entendimento a respeito dos fatos e uma capacidade aumentada para as vocalizações. Esses aspectos do desenvolvimento e do crescimento, de acordo com as mães, contribuíam para a interação e para o comportamento exploratório empreendido pela criança. Isso pode ser visto nos seguintes relatos:

"Ele está mais esperto, ele entende e fala, ele já sabe pedir o
que ele quer, ele demonstra mais do que antes, quando ele quer
alguma coisa, ele demonstra o que ele está sentindo."4; "Eu
acho que agora ele está bem melhor, porque agora ele, mais ou
menos, já sabe pedir as coisas."; "Falar, que nem esses dias,
ela falou 'papai' e 'mamãe' perfeitinho, 'mama', ela pede,
ela quer."; "Ele canta, bate palma. Ele tenta comunicar, tenta
dizer para a gente, às vezes a gente não consegue entender.";
"Começa a caminhar, começa a se expressar mais."; "Bate
palminha, faz bichinho, dá tchau, dá beijo, aprendeu a dizer
não, aprendeu agora a dizer sim, ela começa a dizer sim, aí
ela se atrapalha”.

As mães referiram também que o comportamento do bebê inicialmente caracterizava-se por ser mais passivo, mais calmo e que, com o passar dos meses, foi se alterando, apresentando maior atividade, teimosia e agitação:

“Era quietinha, calma. Agora ela está agitada, bagunceira,
mexe em tudo, mudou bastante coisa, a gente notava que antes
ela era mais calma, mais tranqüila, agora está agitada.”; “Ela
passou a não ser tão passiva para ser mais ativa, sobre todos os
aspectos, tanto motor, quanto de exigências mesmo com relação
às coisas que ela quer e não quer, ela seleciona muito mais e
consegue colocar a vontade dela.”; "Começam a interagir com
tudo, a mudança é bem grande depois de um ano.”; "Está bem
sapeca, agitadinha, teimosinha, muito arteira, bem ativa, não
tem paradeiro".

De acordo com o relato materno, essa maior atividade esteve associada às novas aquisições e habilidades da criança. Observou-se que essas capacidades que mais chamavam a atenção concentraram-se, predominantemente, no comportamento exploratório, e mais especificamente, na locomoção:

"Não pára nunca, nunca, nunca, desde que acorda até a noite. Quer caminhar, quer se mandar correndo, não tem paradeiro.”; "O mais engraçado é que ao invés de descer caminhando, ela chega na pontinha, vem correndo, pára um pouquinho, levanta as pernas e 'tchum'."; "Agora que pode andar, pode ir onde ele quer, em qualquer lugar que ele vai ele fica, mexe em tudo, tudo é novidade."; "Agora ela está descobrindo as coisas, começa andar por tudo quanto é lado.”; “Já está dando os

4 O sinal de ponto-e-vírgula separa o relato das diferentes mães. O relato de uma mesma mãe não foi utilizado para ilustrar mais de uma vez a mesma categoria. 
primeiros passinhos."; Ela passou pela fase de engatinhar, depois de caminhar segurando nas coisas, agora ela está caminhando, pode fazer o que ela tem vontade e está querendo correr também".

As mães também notaram que essas aquisições, nesse momento, possibilitaram à criança explorar os alimentos durante as refeições:

"E eu acho legal que ela aprendeu a dar beijo com barulhinho. E outra coisa que ela está começando a aprender é comer com a mão dela, gosta de brincar com a colher, faz uma sujeirada.";

"Ela brinca bastante, tenta a independência, gosta de pegar comida com a colher".

Além disso, essas novas habilidades permitiram maior manipulação e exploração de objetos presentes no ambiente:

"Ele mexe na TV com o dedinho, no telefone ele já coloca o dedinho para digitar, a caneta, ele pega a caneta, risca e eu não sabia que nessa idade já fazia isso, ele sabe que é para escrever."; "Ela gosta das coisas que não são de brinquedo."; "Nem sempre ele gosta só de um brinquedo, ele gosta de mexer numa gaveta, é uma função”.

Essa maior atividade por parte da criança fazia com que as mães acreditassem que seus filhos podiam tornar-se mais independentes:

“Ela já não é mais o nenezinho, não é mais um bebezinho paradinho, eu até deixo ela no chiqueiro para ver se ela fica mais independente nas coisas dela, mas se ela vê que eu estou fazendo alguma coisa ela já não quer ficar lá, quer ficar comigo, sempre comigo.”; "Ele não fica muito tempo longe de mim, eu digo: 'esse aí, quando nasceu, esqueceram de cortar o cordão umbilical”.

Por outro lado, essas mudanças do desenvolvimento do bebê também foram percebidas pelas mães como um sinal de independência e uma vontade de crescer por parte da criança:

"Cada minuto que vai passando, ela vai ficando com mais vontade de crescer."; "Ela cresceu bastante, principalmente agora que está caminhando, ela está bem mais independente, está falando, mudou a alimentação. É um monte de mudança."; "Ele está evoluindo, está crescendo, eu estou vendo coisas bem saudáveis, bem positivas".

A atividade de brincar também foi apontada pelas mães como algo que lhes chamava a atenção nesse momento do desenvolvimento infantil:

"Ela se entretém com os brinquedos dela, eu ponho uma caixa no quarto, é um descanso, ela fica brincando, coisa mais querida."; "Ele gosta de dançar, cantar, agora já brinca, ele monta, tem um triciclo, gosta que puxe ele, ele gosta de subir em cima da gente de brincar de cavalinho, de subir em cima do sofá".
Essas atividades de brincar e de exploração de objetos foram associadas, por uma das mães, a uma demonstração de inteligência da criança:

"Tu está brincando com ele aqui, ele vai por baixo, quer sair pelas escadas, então me chamou atenção aquilo, que ele tem inteligência de passar por baixo”.

Por fim, outro aspecto que chamou a atenção das mães diz respeito ao fato de a criança ter apresentado capacidade aumentada de atenção e de imitação de comportamentos de adultos, assim como de brincadeira de faz-de-conta:

\footnotetext{
"Adora se arrumar, adora passar batom.”; "Ela já está começando a curtir nanar boneca, ela copia muitos gestos da babá, imita, é impressionante."; "Ela me imita, põe os meus sapatos, ela é observadora. Ela pega a boneca, ela deita a boneca."; "Ela é uma criança muito esperta para a idade dela. Essa forma dela parar para escutar as pessoas, eu quero xingar ela, mas eu converso com ela, ela fica me escutando, ela não fica chorando, nem resmungando, ela fica escutando, é uma coisa que eu admiro."; "Tudo o que ela faz chama atenção porque é diferente. Mas o que ela mais gosta agora é boneca, quase tudo que eu fazia com ela, ela está fazendo com as bonecas. Então de repente ela notava que eu fazia com ela, agora ela está fazendo. Outra coisa que me chama atenção é que ela gosta de pegar panela e colocar comidinha, abre o armário e quer colocar os alimentos dentro, pega a colher e começa a mexer".
}

A partir dos relatos das participantes do presente estudo, pôde-se constatar que as percepções maternas sobre o desenvolvimento da criança aos 12 meses remeteram para as novas aquisições e habilidades, com destaque para a locomoção e a exploração do ambiente por parte da criança aos 12 meses. Os filhos passaram a ser vistos como mais independentes e ativos. As mães também ressaltaram as vocalizações das crianças como contribuindo para a interação mãe-criança e para o comportamento exploratório.

\section{Sentimentos maternos frente às novas aquisições}

Essa categoria diz respeito aos sentimentos maternos decorrentes das novas aquisições em termos do desenvolvimento da criança aos 12 meses. Como subcategorias temáticas destacaram-se: sentimentos negativos ou dificuldades para lidar com as novas aquisições infantis como sentimentos de ansiedade, cansaço e estresse; sentimentos positivos frente ao desenvolvimento e crescimento dos filhos e sentimentos ambivalentes em decorrência das novas habilidades dos filhos aos 12 meses.

Foram relatadas dificuldades em lidar com as novas habilidades da criança:

"Estou achando bem difícil, tu tens que ter muita paciência. É bem difícil, tu conciliar as outras coisas e ele, eu acho pesado, não me sinto bem."; "Me incomoda. Eu tenho um monte de coisas para fazer e ela não deixa”.

As mães também relataram apresentar dificuldades em estabelecer limites às crianças: 
“Eu digo não, não mexe não faz, xingo, mas vou bater nas mãos, para aprender, não pode mexer, mas ela não obedece.”; "A dificuldade que eu sinto mesmo é na parte da educação, quando tem que repreender ele."; "Quando é para impor os limites ou não, então a gente não sabe se está dizendo muito não, eu não sei se a gente não está demais".

A necessidade de colocar limites na criança, de acordo com as verbalizações maternas, acarretou sentimentos de ansiedade, uma vez que as mães pareceram ora temer que a criança tome conta das situações ora tentar respeitar os desejos infantis:

\footnotetext{
“Um pouco ansiosa, cuidadosa, aliás, assim, em relação a pôr os limites eu consigo impor menos do que o meu marido, eu acho que eu tenho que me disciplinar mais."; "Eu fico observando para dar os limites na hora que precisar, não deixar ela tomar conta, e ao mesmo tempo respeitar, o que é claro é difícil, mas a gente vai tentando".
}

A aquisição da habilidade de locomoção apareceu de forma recorrente na fala das mães, uma vez que estas apontaram que a criança, aos 12 meses, exigia uma maior presença, atenção e proximidade física materna:

"Eu tenho que almoçar com ela, para tudo ela tem que estar sempre do meu lado, tudo que eu mexo ela vai atrás, eu vou tomar banho ela vai para o chuveiro, ela está sempre em volta, se ela vê movimento, quer ficar comigo, sempre comigo".

O fato de a criança ter apresentado maior habilidade motora fazia com que as mães tivessem que despender mais tempo, precisando ter maior disponibilidade para acompanhálos em suas atividades:

\footnotetext{
"Brinco um pouquinho, aí eu distraio ela e daí eu saio de mansinho, para ela ficar ali, mas se ela vê que eu saio, ela vai atrás de mim, aí eu tenho que ficar ali o tempo todo em volta, ela quer que eu fique o tempo todo com ela”.
}

Além disso, estas exigências acabavam demandando da mãe realizações de atividades e cuidados simultâneos:

"Se eu estou fazendo alguma coisa na cozinha eu estou falando com ele, cantando, sempre falando com ele.”; “Criança não pára, então tu também não pára, tu tem que estar sempre correndo atrás".

Os relatos maternos também indicaram que essa maior atenção pareceu desencadear sentimentos de cansaço e estresse nas mães:

\footnotetext{
“Eu estou muito cansada, ela não tem paradeiro, essa guria não deixa eu parar, onde eu vou eu tenho que estar com ela junto e tudo tem que estar saindo com ela."; "Teve um tempo que eu estava estressada de ter que cuidar dele, era só eu, eu já estava estressada".
}

E quando houve a possibilidade de deixar a criança com alguém, as mães pareceram sentir-se aliviadas: "Ah, [me sinto] muito bem porque daí eu largo mesmo, eu
largo tudo".

Outro aspecto que surgiu no relato das mães e que pode denotar seus sentimentos frente às novas aquisições em termos de desenvolvimento da criança refere-se à noção de respeito que as mães deveriam ter para com seus filhos:

"Acho que é a natureza dela, tenho que aprender a respeitar isso. É o jeito dela, não tem muito que mudar do gênio dela.”; “A gente respeita sempre. Ela não quer, não quer”.

As mães também perceberam a necessidade de respeitar o ritmo próprio do crescimento da criança:

"Eu acho que ele se sente seguro, ele fica em pé super bem. Mas aí, para dar o passinho, ele dá uns cinco, seis passos, sozinho e cai. Mas eu acho que vai dar mais um tempo pra ele caminhar".

A negociação surgiu nos relatos maternos como forma de lidar com a criança nesse período do seu desenvolvimento:

"Chega uma hora que eu vejo que não está dando, aí eu largo de mão ou digo, 'ah, não dá mesmo para fazer? Será que não dá,".

Percebeu-se que, ao mesmo tempo em que a exigência de maior tempo e de proximidade física por parte da criança foi relatada como algo excessivo, a maternidade pareceu conferir às mães uma capacidade aumentada de dar conta dessas demandas que surgem nesse período:

"Vai sair de ti força suficiente para fazer as coisas que são necessárias”.

As mães relataram que tal solicitação era passageira, constituindo-se em uma fase do desenvolvimento infantil:

"Ele quer descobrir tudo, às vezes me falta paciência, mas isso é uma fase, depois passa”.

Mesmo que esse momento do desenvolvimento tenha sido entendido como transitório, as mães acreditavam que deviam acompanhar o crescimento da criança, uma vez que a percebiam como alguém dependente de seus cuidados, de seus ensinamentos e de sua dedicação:

"Acho que o fato da gente gerar uma criança. Ela depende de mim, depende do que eu ensinar, do que eu passar para ela, depende da minha atenção, então é um ser dependendo de ti o tempo inteiro.”; "Nessa idade a criança depende do adulto, ela quer fazer tudo, mas quando a criança cai, acontece alguma coisa é porque o adulto não cuidou".

As novas aquisições da criança também mobilizaram sentimentos de contentamento por parte das mães:

"Está começando a falar, então isso me mobiliza bastante, o carisma dela me mobiliza. Ela é muito querida, eu fico muito 
contente com isso.”; "Eu acho legal, eu gosto de ver. Eu disse para ela deixar de engatinhar e caminhar, incentivo bastante, eu acho legal, perninha bem aberta, ela não tem firmeza total, mas eu acho muito bonito.”; "Eu fico fascinada de ficar vendo ele caminhar."; "Eu estou curtindo, é que agora eu entendo, eu converso com ele, eu estou me sentindo bem melhor."; "Esses dias ele estava na motoquinha e eu quase chorei de emoção. Ele desceu da motoquinha sozinho, é uma fase que ele está aprendendo a se virar sozinho. Ele já engatinha desde os sete, oito meses, e agora ele está querendo dar os primeiros passos. Então, para mim, tudo o que ele faz sozinho é ótimo, isso de tentar fazer as coisas sozinho, de caminhar e descer da motoquinha sozinho, ele está aprendendo muita coisa."; "Eu fiquei feliz, quando ele caminhou a primeira vez! Contei para todo mundo que ele estava caminhando".

Essas novas aquisições da criança levaram as mães a pensar que seus filhos acreditavam ter ficado mais independentes:

"E outra coisa que ela está começando a aprender é comer com a mão dela, claro que ela faz uma bagunça, mas ela está ficando... eu acho que ela se sentiu 'ah, aprendi alguma coisa, agora sou independente, agora não preciso mais da mãe para isso', claro que precisa, mas ela fica toda hora com aquela colher".

As mães mostraram-se ainda emocionadas ao falarem sobre os sentimentos despertados pela relação materno-filial:

\begin{abstract}
"Amor, é assim, é isso aí a nossa relação, a gente se olha e já sabe o que quer."; "É maravilhoso, acompanhar isso, para mim é muito bonito. Todo mundo dizia que é maravilhoso ter filho, que limita muitas coisas, mas é muito legal, tu acompanhando, ver ele começar a descobrir as coisas. É bonito de ver ele aprendendo". "É legal, tu ver a criança fazendo coisas, que ela não fazia antes, porque tem coisas que eu acho que tem que deixar a criança experimentar, para que ela mesma possa sair daquilo ali".
\end{abstract}

Conforme mencionado pelas mães, a capacidade ampliada da criança de explorar o ambiente acabava exigindo cuidados maternos diferenciados nesse período do desenvolvimento infantil:

"É uma nova fase, que tu curte de outra maneira cada descoberta, tu está descobrindo junto, eu sou muito de querer descobrir junto com ele as coisas, como eu estaria vendo se eu tivesse um aninho, não ir mostrando para ele, 'ah meu filho isso aqui é assim'... ir descobrindo junto".

Por fim, os relatos também apontaram que as mães, nesse momento, apresentavam uma capacidade de compreender e decodificar as necessidades da criança:

"Tu aprende a saber o que é que ela está querendo, às vezes, algumas coisas são mais difíceis por ela não falar ainda, não saber dizer o que quer. Mas tu vai sabendo, até o choro, se ela está com alguma dor, se ela está querendo mamar, com fome, ou se está querendo dormir".
Pode-se notar, ainda, uma ambivalência por parte das mães quanto ao fato de estarem se dedicando em demasia às suas tarefas profissionais:

"Quando tu está em casa, tu fica até um pouco irritada de estar em casa e ele bagunçando tudo, a gente fica até meio enjoada de ser mãe, mas aí eu comecei a trabalhar, como a gente sente falta dele. É uma falta que eu sinto."; "A vontade era de poder fazer mais, se eu não trabalhasse e pudesse me dedicar mais a ela, o tempo dela está passando e eu não estou dando tudo, mas depois eu penso 'eu não posso anular a minha vida em função dela, porque um dia ela vai se tornar independente e eu vou ter largado toda a minha vida para dar atenção a ela' e quem sabe um dia até ela vai viajar, morar em outro lugar e eu vou ficar sem ela".

Em contraposição, houve mães que relataram sentir falta dos bebês quando tinham de se afastar dos mesmos:

"Fico com saudade, louca para chegar em casa: 'Como será que está a minha filha?'”.

As mães mencionaram, ainda, que apresentavam dificuldades com relação aos momentos de separação de seus filhos:

"É que na verdade, eu acho que eu estou bem receosa, com receio dessa coisa da minha separação dela, será que a criança também não tem essa capacidade de elaborar e de assimilar, e chorar um pouco e depois ver que está bom? Tem?!”; "Eu comecei a ir numa psicóloga para eu largar ele, porque sou muito grudada nele, sou neurótica por ele, saio de casa, mas fico o tempo inteiro pensando nele, se eu vou num lugar saio daquele lugar e vou para outro, neste trajeto de carro eu já ligo, para saber como ele está, se ele comeu”.

Percebeu-se, também, ambivalência por parte das mães no que diz respeito aos movimentos de distanciamento e de separação física com relação ao bebê. Por um lado, pareceu haver a gratificação e a realização em ver seu filho adquirir maiores habilidades, por outro pareceu existir sentimentos de bem-estar de que este permanecesse em seus braços:

"Como é bom quando eles ficam só no colo da gente, tão pertinho, mas é muito gratificante ver o teu filho aprendendo a caminhar".

As mães relataram realizar todas as vontades de seus filhos, nesse momento, uma vez que acreditavam que estes eram muito dependentes de seus cuidados:

"Eu acho que eu faço muito a vontade dela, eles são tão pequininhos, tão dependentes da gente que eu tenho pena de deixar, por exemplo ela chorando, eu faço todas as vontades dela."; "Eu vivo muito para ele, então tem mães e mães, umas mães são voltadas para o filho como eu”.

Algumas mães apresentavam, ainda, desejo de que a criança permanecesse eternamente um bebê: 
"Acho que a mãe não quer que o nenê cresça nunca, acho que as mães são assim”.

Enquanto, outras apresentavam desejo de maior independência por parte da criança:

“Não está caminhando ainda, eu acho que ele está preguiçoso,
com um pouco de medo, ele nunca caiu assim.”; “Eu que-
ria que ela já estivesse caminhando, até para me facilitar
mais.”; "Eu não vejo a hora de caminhar, daí primeiro eu
queria que engatinhasse, queria porque queria. Daí dá um
trabalho, tem que estar sempre atrás, sempre de olho. Daí
agora caminha, daí dizem que quando caminhar vai ser pior
ainda.”; "Ele cada vez está mais ágil, eu sinto que a qualquer
momento vai sair andando, a gente já nota isso, ele está se
equilibrando. Hoje mesmo ele subiu naquele carrinho dele,
desceu com a maior agilidade, que ontem ele já não estava
tão ágil assim”.

As mães pareceram também cobrar a si próprias quanto ao fato de não terem a paciência que gostariam de possuir frente às demandas da criança nesse momento:

“Eu estou superfeliz, super com tudo. Eu gosto de tudo nela. Às
vezes me irrito um pouco com ela, eu acho que às vezes eu não
tenho muita paciência. Tenho umas atitudes meio autoritárias.”;
"Eu tenho paciência, mais do que eu tinha antes, mas às vezes
eu acho que eu não estou sendo paciente o suficiente ou que
não estou compreendendo o suficiente, tu quer dar mais do que
tu tem, do que tu pode dar, é um tipo de cobrança”.

As mães perceberam que a criança era capaz de explorar o ambiente, ainda que necessitando do amparo e do cuidado materno. Diante disso, as mães tenderam a deixar a criança mais solta e mais livre. Ao mesmo tempo em que incentivaram os movimentos de afastamento, também se preocuparam em estar sempre atentas e cuidadosas:

"Eu procuro suprir todas as necessidades dela. Lógico, eu deixo ela mais solta, deixo ela mais livre, eu não fico ali em cima, dependurada, 'não faz assim, não faz', eu deixo ela fazer, às vezes ela cai. Eu cuido para não ser uma coisa muito grave. Aí eu deixo ela experimentar e ver as coisas difíceis". "[Ele gosta] de pular, de sapatear, de se jogar. Quando ele se joga eu deixo. Ele se quer, se joga, aí eu seguro ele. Aí ele quer se jogar, eu fico cuidando onde ele se joga, e largo ele no chão. Quer se jogar, se joga. Aí ele se joga, olha para mim e faz. 'Hã...!' Mas não chora.”; "Eles são mais independentes. Eu tenho que estar sempre olhando, mas ao menos ele não está sempre no meu colo".

Os relatos mostram a diversidade e intensidade dos sentimentos maternos nesse momento do desenvolvimento da criança. Muitas das novas aquisições parecem exigir das mães novas adaptações e aparecem associadas a sentimentos específicos de ansiedade, cansaço, estresse e também de contentamento. Foram também relatados sentimentos ambivalentes, apontando para uma satisfação ao acompanhar o crescimento e desenvolvimento da criança e, por vezes, insinuando a vontade de que o filho permanecesse um bebê.

\section{Discussão}

Os resultados do presente estudo revelaram que os sentimentos maternos sobre o desenvolvimento e o crescimento da criança aos 12 meses estiveram marcadas pelas novas aquisições da criança. As mães destacaram que naquele momento a criança estava passando de uma passividade para uma maior atividade e agitação. Relataram ainda que, nessa faixa etária, o bebê apresentava maior habilidade motora, de linguagem, de manipulação e de exploração de objetos e do ambiente. Em particular, as vocalizações contribuíram para a interação mãe-criança e para o comportamento exploratório. Embora este artigo enfoque a criança aos 12 meses de idade, cabe ressaltar que as novas aquisições e habilidades adquiridas nesse período continuam ocorrendo ao longo do desenvolvimento infantil.

As várias aquisições apontadas pelas mães do presente estudo refletem que a seqüência do aparecimento de habilidades motoras sucessivas seria praticamente a mesma entre as crianças, com variações apenas na rapidez de sua progressão (Mazet \& Stoleru, 1990). A criança evolui, em alguns meses, de um estado falho e descoordenado para um estado em que se torna capaz de segurar objetos de maneira fina e com mais facilidade e de deslocar-se por meio do caminhar. Há um aumento da capacidade de atenção, maior interesse por objetos de seu ambiente e apresenta maior comunicação com sua mãe. A criança passa grande parte de seu tempo de brinquedo explorando e manipulando objetos, colocando coisas na boca, sacudindo e movimentando-as pelo chão, o que lhe permite compreender as possíveis maneiras de explorar os objetos (Bee, 1997; Fenson \& cols., 1974; Ruddy \& Borenstein, 1982). Assim, não é apenas a qualidade das percepções infantis que evolui, mas igualmente a quantidade de informações sensoriais que a criança é capaz de tratar em um tempo determinado (Mazet \& Stoleru, 1990).

Os relatos maternos apresentados no presente estudo confirmam que as novas aquisições das crianças conduziram-nas a uma maior atividade, independência, comunicação, bem como favoreceram as brincadeiras e interações com a mãe. Sabe-se que o comportamento exploratório da criança está associado a alguns marcos importantes do desenvolvimento motor, como engatinhar em direção a algo que chama a atenção e caminhar com apoio de objetos, entre outros (McKenzie \& cols., 1995; Papalia, Olds \& Feldmann, 2006). O comportamento exploratório tem sido visto também como um importante meio de a criança obter informações sobre o ambiente, com implicações para o desenvolvimento de sua habilidade cognitiva (Caruso, 1993; Gibson, 1987; Ruddy \& Borenstein, 1982), tendo em vista a complexidade dos movimentos de exploração que incluem o olhar, mexer, sacudir e levar objetos à boca (Ruff, 1989). O desenvolvimento de habilidades motoras ocorre em uma seqüência de atos que vão dos mais simples para os mais complexos, sendo que essas aquisições não são explicadas apenas pela maturação, mas também pelo contexto físico e social em que o bebê vivencia suas explorações (Thelen, 1995). Nesse sentido, criança e ambiente formam um sistema interligado. A exploração física do meio levaria o bebê a experimentar novas emoções ao ter de se distanciar de seus cuidadores. 
No presente estudo, as mães também salientaram que os seus bebês aos 12 meses apresentavam novas habilidades motoras denotando uma posição mais ativa na determinação da proximidade e distanciamento da mãe pela locomoção. Essa maior atividade e agitação por parte da criança contribuíram para que as mães percebessem seus filhos como mais independentes ou levaram-nas a desejar que estes adquirissem tal independência. Nessa fase do desenvolvimento, em que há uma maior capacidade para o distanciamento físico, o bebê também vivencia sentimentos de ambivalência com medo de se distanciar e do seu desejo de comportar-se de forma independente (Brazelton, 2002; Mahler, 1979/1982). A mãe, em especial, torna-se emocionalmente mais importante nesses períodos uma vez que o bebê está desenvolvendo um senso de necessidade de sua presença (Mahler, 1979/1982; Mahler \& cols., 1975/2002; Winnicott, 1979/1983; 1965/2001; Stern, 1991). De acordo com Mahler (1979/1982), a criança vivencia ora satisfação em atuar de forma independente, ora ansiedade frente a essas separações. A criança, em seu processo evolutivo, passa a experienciar realizações em separado, as quais são sucessivamente prazerosas e ameaçadoras. A autora também postulou que a predominância do prazer nas atuações independentes e a disponibilidade materna possibilitam à criança conter a ansiedade de separação surgida em suas experiências. Dessa maneira, o ambiente de confiabilidade proporcionado pelos cuidados maternos propicia o funcionamento individual da criança (Mahler, 1979/1982; Mahler \& cols., 1975/2002).

Essa maior possibilidade de manifestar a independência física tem sido caracterizada como um dos momentos críticos do desenvolvimento infantil, uma vez que ocorre um avanço particularmente intenso nas habilidades da criança, constituindo-se como um desafio para os pais (Brazelton, 2002; Wenar, 1972). Alguns estudos examinaram as atitudes maternas na criação dos filhos aos 12 meses (Benasich \& Brooks-Gunn, 1996), enquanto outros enfatizaram a competência e auto-eficácia materna (Teti \& Gelfand, 1991; Veddovi \& cols., 2004), a sensibilidade materna na interação com a criança de 12 meses (Kivijärvi \& cols., 2001; Lohaus \& cols., 2004), os efeitos da interferência materna (Gray \& cols., 1979), além da parentalidade e o desenvolvimento da criança de um ano de idade (Van Bakel \& Riksen-Walraven, 2002), porém não abordaram a temática de sentimentos frente às aquisições durante o primeiro ano de vida.

Os resultados do presente estudo revelaram que as mães tendiam a refletir sobre suas formas de cuidado, ensinamentos e dedicação à criança. Elas procuravam se utilizar de negociações e respeito ao filho quando interagiam com as suas novas aquisições. Contudo, percebeu-se ambivalência por parte de algumas mães. Por um lado, os relatos indicaram gratificação e realização por parte das mães ao perceber o desenvolvimento de seu bebê. Elas mencionaram sentimentos de contentamento e bem-estar ao perceber as novas aquisições e habilidades da criança. Por outro lado, as mães verbalizaram que os bebês demandavam maior dedicação, atenção e proximidade física, especialmente devido às novas aquisições motoras e exploração do ambiente. As novas capacidades de locomoção denotaram uma posição mais ativa do bebê na determinação da proximidade e de distanciamento com relação à mãe. Frente a isso, relatos maternos revelaram sentimentos de cansaço e estresse. Isso também acabou ocasionando sentimentos de cobrança quanto ao fato de quererem ter mais paciência e maior tempo para acompanhar o crescimento de seus filhos. Por vezes, a maior independência da criança suscitou algumas manifestações de que o filho(a) permanecesse bebê.

Os resultados do presente estudo corroboram achados da literatura, uma vez que esta refere que a dinâmica da separação mãe-bebê não é vivida unicamente pela criança (Brazelton, 2002; Mazet \& Stoleru, 1990; Mahler, 1979/1982; Mahler \& cols., 1975/2002). As novas aquisições e conseqüente independência do bebê e a maneira como este, aparentemente, tende a se desapegar da figura materna refletem-se nas emoções e comportamentos da própria mãe, que também pode confrontar-se com a angústia de separação em relação a seu filho. Já o modo como a mãe experiencia seus sentimentos de angústia se refletirá mais ou menos positivamente na independência da criança. Se a mãe não tolera a separação que lhe é imposta pelo bebê acaba por interferir nesse importante processo, mantendo o bebê em um estado de dependência para com ela (Brazelton, 2002; Mazet \& Stoleru, 1990; Mahler, 1979/1982; Mahler \& cols., 1975/2002).

Nesse contexto, a mãe ocupa papel fundamental, uma vez que precisa adaptar-se às necessidades decorrentes da capacidade ampliada da criança de explorar o ambiente. Embora tal fase tenha sido percebida pelas mães do presente estudo como passageira, elas mencionaram que essas novas aquisições demandaram maior proximidade, presença física e disponibilidade materna para acompanhar seus filhos em suas atividades de exploração. Para Mazet e Stoleru (1990), o estado afetivo materno, bem como as palavras que a mãe usa para nomear objetos, facilitam ou não a exploração do meio pela criança.

No mesmo sentido, Elkind (2004) apontou que a iniciativa, a curiosidade e a exploração de uma criança é o resultado saudável da experiência com seus cuidadores. Se nesse ambiente suas necessidades são satisfeitas de maneira consistente e adequada, a sensação de confiança se estabelece e passa a estender-se às demais pessoas. Assim, a iniciativa, a curiosidade e a exploração são fortalecidas quando os pais reservam um tempo para responder às demandas dos filhos e quando são capazes de tolerar a "bagunça" decorrente dos movimentos exploratórios do bebê. Outro fato que favorece o surgimento da curiosidade e iniciativa da criança, segundo esse autor, é a oportunidade de proporcionar materiais para exploração e descoberta, bem como disponibilizar tempo para as investigações infantis em um ambiente compreensivo.

No presente estudo, ao mesmo tempo em que as mães se preocuparam com as explorações de seus filhos, tendiam a incentivá-los nas suas realizações. Mahler (1963/1979) enfatizou que a mãe é o suporte da evolução psicoafetiva do bebê e que seu papel deve se moldar constantemente para se adaptar às necessidades próprias do ritmo da criança. Essa idéia assemelha-se a noção de mãe suficientemente boa de Winnicott (2000). Para Winnicott, além da adaptação ativa inicial, a mãe também deve promover uma falha gradual nessa adaptação. Isso dependerá da capacidade individual do bebê de suportá-la ou tolerá-la por meio da atividade e da compreensão mental (Winnicott, 2000). Esse papel primordial 
do ambiente torna a criança forte e estável até que possa ficar livre do apoio da mãe e do pai e alcançar a separação mental dos mesmos, constituindo um self pessoal e separado (Mahler, 1979/1982; Mahler \& cols., 1975/2002). Dessa forma, a criança pode separar-se de seus cuidadores, tornando-se capaz de estabelecer relações com o mundo e constituir um senso de self individualizado.

Considerando o exposto, os resultados do presente estudo apontam para a importância das interações estabelecidas entre a mãe e o seu filho(a) aos 12 meses de idade, tendo em vista as novas aquisições da criança e os sentimentos advindos das percepções maternas sobre o desenvolvimento infantil. Enquanto algumas mães relataram satisfação pelo crescimento do bebê, outras disseram estar preocupadas com as adaptações e cuidados decorrentes desse período. Esses sentimentos constituem-se em um importante fator que contribui para a qualidade da relação mãe-criança. Cabe ressaltar que os resultados apresentados referem-se à amostra estudada, composta por 28 mães participantes. Assim não se pode afirmar que as considerações finais deste estudo sejam passíveis de generalização. Portanto, sugere-se que outros estudos examinem questões ligadas aos sentimentos frente ao desenvolvimento da criança aos 12 meses que permeiam as relações que se estabelecem nos diferentes subsistemas familiares. Novas investigações, além de ampliarem a discussão sobre essa temática, podem auxiliar os profissionais na compreensão e na elaboração de propostas de intervenção junto a crianças e suas mães que precisam se adaptar a esse período de importantes e novas aquisições por parte da criança.

\section{Referências}

Ainsworth, M., Blehar, M., Waters, E. \& Wall, S. (1978). Patterns of attachment. Hillsdale: Erlbaum.

Bardin, L. (1977). Análise de Conteúdo. (L. A. Reto \& A. Pinheiro, Trad.). Lisboa: Edições 70.

Bee, H. (1997). O ciclo vital (R. Garcez, Trad.). Porto Alegre: Artes Médicas.

Benasich, A. A. \& Brooks-Gunn, J. (1996). Maternal attitudes and knowledge of child-rearing: association with family and child outcomes. Child Development, 67, 1186-1205.

Bowlby, J. (1989). Uma base segura. (S. M. de Barros, Trad.). Porto Alegre: Artes Médicas.

Brazelton, T. B. (2002). Momentos decisivos do desenvolvimento infantil. ( $2^{\mathrm{a}}$ ed., J. L. Camargo, Trad.). São Paulo: Martins Fontes.

Caruso, D. A. (1993). Dimensions of quality in infant's exploratory behavior: relationships to problem-solving ability. Infant Behavior and Development, 16, 441-454.

Elkind, D. (2004). Sem tempo para ser criança: a infância estressada. (M. F. Lopes, trad.). Porto Alegre: Artes Médicas.

Fenson, L., Sapper, V. \& Minner, D. C. (1974). Attention and manipulative play in the one-year-old child. Child Development, 45(3), 757-765.

Gibson, E. J. (1987). Exploratoy behaviour in the development of perceiving, acting and the acquiring of knowledge. Annual Review of Psychology, 39, 1-41.

Gray, M. D., Tracy, R. L. \& Lindberg, C. L. (1979). Effects of maternal interference on the attachment and exploratory behavior of oneyear-olds. Child Development, 50, 1211-1214.
Grupo de Interação Social, Desenvolvimento e Psicopatologia - GIDEP/UFRGS/CNPq (1998a). Entrevista sobre a Experiência da Maternidade e o Desenvolvimento da do Bebê aos 12 meses. Instrumento não-publicado. Instituto de Psicologia. Universidade Federal do Rio Grande do Sul.

Grupo de Interação Social, Desenvolvimento e Psicopatologia - GIDEP/UFRGS/CNPq (1998b). Ficha de Contato Inicial. Instrumento não-publicado. Instituto de Psicologia. Universidade Federal do Rio Grande do Sul.

Grupo de Interação Social, Desenvolvimento e Psicopatologia - GIDEP/UFRGS/CNPq (1998c). Entrevista de Dados Demográficos. Instrumento não-publicado. Instituto de Psicologia. Universidade Federal do Rio Grande do Sul.

Hollingshead, A. (1975). The four-factor index of social status. Yale University. (Manuscrito não-publicado)

Johnson, D. \& Brody, N. (1977). Visual habituation, sensorimotor development and tempo of play in one-year old infants. Child Development, 48(1), 315-320.

Kivijärvi, M., Voeten, M. J. M., Niemelä, P., Räihä, H., Lertola, K. \& Piha, J. (2001). Maternal sensitiviy behavior and infant behavior in early interaction. Infant Mental Health Journal, 22(6), 627-640.

Laville, C. \& Dionne, J. (1999). A construção do saber: manual de metodologia de pesquisa em ciências humanas (H. Monteiro \& F. Settineri, Trad.) Porto Alegre: Artes Médicas.

Lohaus, A., Keller, H., Ball, J., Voelker, S. \& Elben, C. (2004). Maternal sensitivity in interactions with three- and 12-monthold infants: stability, structural composition and developmental consequences. Infant and Child Development, 13, 235-252.

Mahler, M. (1963). Reflexões sobre o desenvolvimento e a individuação. O processo de separação-individuação $($ H. M. de Souza, Trad.). Porto Alegre: Artes Médicas. (Trabalho original publicado em 1979)

Mahler, M. (1982). O processo de separação-individuação. $(\mathrm{H}$. M. de Souza, Trad.). Porto Alegre: Artes Médicas. (Trabalho original publicado em 1979)

Mahler, M., Pine, F. \& Bergman, A. (2002). O nascimento psicológico da criança: Simbiose e Individuação. (J. A. Russo, Trad.). Porto Alegre: Artes Médicas. (Trabalho original publicado em 1975).

Mancini, M. C., Teixeira, S., Araújo, L., Paixão, M. L., Magalhães, L. C., Coelho, Z., Gontijo, A., Furtado, S., Sampaio, R. \& Fonseca, S. (2002). Estudo do desenvolvimento da função motora aos 8 e 12 meses de idade em crianças nascidas pré-termo e a termo. Arquivos de Neuropsiquiatria, 60(4), 974-980.

Mazet, P. \& Stoleru, S. (1990). Manual de psicopatologia do recémnascido. (F. F. Settineri, Trad.). Porto Alegre: Artes Médicas.

McKenzie, B. E., Lawrence, D. A. \& Connell, S. (1995). The spatial coding strategies of one-year-old infants in a locomotor search task. Child Development, 66, 937-958.

Newcombe, N. (1999). Desenvolvimento infantil: abordagem de Mussen. ( $8^{\mathrm{a}}$ ed., C. Buchweitz, Trad.). Porto Alegre: Artes Médicas.

Papalia, D. E., Olds, S. W. \& Feldman, R. D. (2006). (8 ${ }^{\mathrm{a}}$ ed., D. Bueno, Trad.). Desenvolvimento humano. Porto Alegre: Artes Médicas.

Piccinini, C., Tudge, J., Lopes, R. C. S. \& Sperb, T. (1998). Estudo longitudinal de Porto Alegre: da gestação à escola. Projeto de Pesquisa, Instituto de Psicologia, Universidade Federal do Rio Grande do Sul. 
Prado, L. C. (1996). (org.). Famílias e terapeutas: construindo caminhos. Porto Alegre: Artes Médicas.

Ribas, A. F. \& Seidl de Moura, M. L. (2004). Responsividade e teoria do apego: uma discussão crítica do papel de estudos transculturais. Psicologia: Reflexão e Crítica, 17(3), 315-322.

Ruddy, M. G. \& Borenstein, M. H. (1982). Cognitive correlates of infant attention and maternal stimulation over the first year of life. Child Development, 53, 183-188.

Ruddy, M. G. \& Bornstein, M. H. (1982). Cognitive correlates of infant attention and maternal stimulation over the first year of life. Child Development, 53, 183-188.

Ruff, H. A. (1989). The infants' use of visual and haptic information in the recognition of objects. Canadian Journal of Psychology, 43, 302-319.

Schwengber, D. \& Piccinini, C. A. (2004). Depressão materna e interação mãe-bebê no final do primeiro ano de vida. Psicologia: Teoria e Pesquisa, 20(3), 233-240.

Stern, D. (1991). Diário de um bebê: o que seu filho vê, sente e vivencia (D. Batista, Trad.). Porto Alegre: Artes Médicas.

Teti, D. M. \& Gelfand, D. M. (1991). Behavioral competence among mothers of infants in the first year: the mediational role of maternal self-efficacy. Child Developmente, 62(5), 918-930.

Thelen, E. (1995). Motor development: a new synthesis. American Psychologist, 50(2), 79-95.

Tudge, J. R. H. \& Frizzo, G. F. (2002). Classificação baseada em Hollingshead do nível sócio-econômico das famílias do estudo longitudinal de Porto Alegre: da gestação à escola. Manuscrito não publicado. Instituto de Psicologia, Universidade Federal do Rio Grande do Sul.
Van Bakel, H. J. A. \& Riksen-Walraven, J. M. (2002). Parenting and development of one-year-olds: Links with parental, contextual, and child characteristics. Child Development, 73, 256-273.

Veddovi, M., Gibson, F., Kenny, D. T., Bowen, J. \& Starte, D. (2004). Preterm behavior, maternal adjustment and competences in the newborn period: what influence do they have at 12 months postnatal age? Infant Mental Health Journal, 25(6), 580-600.

Wenar, C. (1972). Executive competence and spontaneous social behavior in one-year-olds. Child Development, 43, 256-260.

Winnicott, D. W. (1983). O ambiente e os processos de maturação. (I. C. S. Ortiz, Trad.). Porto Alegre: Artes Médicas. (Trabalho original publicado em 1979)

Winnicott, D. W. (1999). Tudo começa em casa. (P. Sandler, Trad.). São Paulo: Martins Fontes. (Trabalho original publicado em 1989)

Winnicott, D. W. (2000). Da pediatria à psicanálise: Obras escolhidas. (D. L. Bogomoletz, Trad.) Rio de Janeiro: Imago.

Winnicott, D. W. (2001). A família e o desenvolvimento individual ( $2^{a}$ ed., M. B. Cipolla, Trad.). São Paulo: Martins Fontes. (Trabalho original publicado em 1965)

Zamberlan, M. A. T. (2002). Interação mãe-criança: enfoques teóricos e implicações decorrentes de estudos empíricos. Estudos de Psicologia, 7(2), 399-406.

Recebido em 31.10.2005

Primeira decisão editorial em 10.02.2006

Versão final em 16.05.2006

Aceito em 26.01.2007 